\title{
What factors affect the length of hospitalization in patients with erysipelas? A 10-year retrospective study of patients hospitalized in Lower Silesia, Poland
}

\author{
Magdalena Łyko ${ }^{1, B-D}$, Mateusz Kaczmarek ${ }^{1, B, D}$, Polina Nekrasova ${ }^{1, B, D}$, \\ Anita Hryncewicz-Gwóźdźz',E, Joanna Maj2, ${ }^{2, E}$, Alina Jankowska-Konsur ${ }^{2, A, C, C, F}$ \\ ${ }^{1}$ Student Research Group of Experimental Dermatology, Department of Dermatology, Venereology and Allergology, Wroclaw Medical University, Poland \\ ${ }^{2}$ Department of Dermatology, Venereology and Allergology, Wroclaw Medical University, Poland \\ A - research concept and design; $B$ - collection and/or assembly of data; $C$ - data analysis and interpretation; \\ $D$ - writing the article; $E$ - critical revision of the article; $F$ - final approval of the article
}

Address for correspondence

Anita Hryncewicz-Gwóźdź

E-mail: anhryn@gmail.com

Funding sources

None declared

Conflict of interest

None declared

Received on November 9, 2020

Reviewed on November 16, 2020

Accepted on May 10, 2021

Published online on August 18, 2021

Cite as

Łyko M, Kaczmarek M, Nekrasova P, Hryncewicz-Gwóźdź A, Maj J, Jankowska-Konsur A. What factors affect the length of hospitalization in patients with erysipelas? A 10-year retrospective study of patients hospitalized in Lower Silesia, Poland. Adv Clin Exp Med. 2021;30(9):981-985.

doi:10.17219/acem/136504

DOI

10.17219/acem/136504

Copyright

Copyright by Author(s)

This is an article distributed under the terms of the

Creative Commons Attribution 3.0 Unported (CC BY 3.0)

(https://creativecommons.org/licenses/by/3.0/)

\section{Abstract}

Background. Erysipelas is an acute skin infection caused by group $A$ and $G$ streptococci. This infection is associated with many comorbidities and often requires hospitalization.

Objectives. The aim of this study was to identify the factors related to the length of hospitalization in patients with erysipelas.

Materials and methods. This retrospective study included 153 admissions of 135 patients $(63$ women and 72 men) hospitalized due to erysipelas from January 2010 to December 2019. Clinical symptoms, test results, comorbidities, and antibiotic treatments were taken into consideration as factors affecting the length of hospital stay.

Results. The median length of hospitalization was 10 days (interquartile range $(I Q R)=7-14)$. Women spent less time in the ward, but the difference was not significant. Features such as tinea pedis (15.5 days, $I Q R=13.5-20 ; p=0.002)$, anemia (11 days, IQR $=9-15 ; p=0.02$ ), chills (12 days, IQR $=9-15 ; p=0.03)$, elevated serum (-reactive protein (CRP) level over 100 mg/L (11 days, IQR $=8-17 ; p=0.02$ ), and leukocytosis (11 days, IQR $=8-15, p=0.005$ ) were identified as prolonged hospitalization factors. Moreover, patients with erysipelas localized to the legs $(p=0.01)$ and with a gangrenous variant of erysipelas $(p=0.03)$ were hospitalized longer. The first-choice antibiotic was not significant in terms of prolonged hospitalization. Patients treated with clindamycin during hospitalization, regardless of whether it was a first-line or subsequent antibiotic, stayed in the ward significantly longer $(p=0.005)$.

Conclusions. Patients suffering from erysipelas with the features identified above, have a higher risk of a prolonged stay in the hospital. Significantly increased inflammatory factors, anemia and tinea pedis contributed to prolonged hospitalization.

Key words: therapy, hospitalization, antibiotics, erysipelas, clindamycin 


\section{Background}

Erysipelas is an acute infection of the dermis and the subcutaneous tissues, most commonly localized to the lower limbs and the face. ${ }^{1-3}$ This infection mainly affects adults and older people, has a repetitive nature, and is associated with certain comorbidities, including tinea pedis and diabetes. ${ }^{1-4}$ The acute infection is primarily caused by group A (Streptococcus pyogenes) and group G $\beta$-hemolytic streptococci. ${ }^{1-7}$ Diagnosis is usually made based on clinical features including local erythema with a clearly demarcated margin that is associated with pain and edema, as well as general symptoms (fever, chills, nausea, and malaise). ${ }^{1-4,7-9}$ Guidelines for the management of skin and soft tissue infections are typically based on expert opinion and pathophysiological considerations. However, antibiotic therapy for erysipelas is most often empirical and depends on the clinical experience of the treating physician. ${ }^{10-13}$ Erysipelas is a common cause of hospitalization, including prolonged and repetitive hospitalizations that generate high costs for the healthcare system.

\section{Objectives}

This study aimed to identify the factors affecting the length of hospitalization in patients admitted to the dermatology department due to erysipelas.

\section{Materials and methods}

\section{Study design}

The study was based on an analysis of clinical data from patients hospitalized due to erysipelas in the department of dermatology. Patients admitted for erysipelas treatment from January 2010 to December 2019 were enrolled in the study. Data analyses included identified risk factors for erysipelas development, inflammatory parameters measured upon admission to the hospital (C-reactive protein (CRP), procalcitonin, erythrocyte sedimentation rate (ESR), leukocytosis), the results of microbiological swabs, and applied antibiotic treatments. The obtained data were compared in order to examine their impact on the length of hospitalization (Table 1).

\section{Setting and participants}

The study was conducted in the Department of Dermatology, Venereology and Allergology at Wroclaw Medical University. Patients admitted for erysipelas treatment during the period of time from January 1, 2010 to December 31, 2019 were identified in the hospital electronic database using the International Classification of Diseases, $10^{\text {th }}$ revision (ICD-10) code A46 (erysipelas).
In the analyzed period, 153 hospitalizations were identified. This corresponded to 135 patients (63 women and 72 men, mean age $61.2 \pm 16.8$ years) who were included in the study. The number of admissions exceeded the number of patients due to repeated hospitalizations of patients with relapses. The demographics and clinical characteristics of the study population are summarized in Table 1.

\section{Statistical analyses}

Statistical analyses were performed using STATISTICA v. 13 software (StatSoft Inc., Tulsa, USA). The quantitative variables were described using median, range, interquartile range (IQR), and means \pm standard deviations (SD). The relationships between the length of hospitalization and the factors were examined using the Mann-Whitney U test. To compare more than 2 groups the Kruskal-Wallis one-way analysis of variance (ANOVA) was used. Values of $\mathrm{p}<0.05$ were considered statistically significant.

\section{Results}

The median length of hospitalization was 10 (IQR = 7-14) days. Regarding sex, the median length of hospitalization in women was slightly shorter than in men, but the difference was not significant ( 9 days, IQR $=7-14$ compared to 10 days, IQR $=7-14$, respectively; $\mathrm{p}>0.05)$. Neither age nor the number of episodes were associated with prolonged stay in the hospital.

Patients suffering from tinea pedis stayed in the hospital significantly longer than those without this condition (15.5 days, IQR $=13.5-20$ compared to 9 days, IQR $=7-14$, respectively; $\mathrm{p}=0.002$ ). In addition, anemia was associated with prolonged hospitalization ( $\mathrm{p}=0.03$; Table 2$)$. Diabetes mellitus, venous insufficiency, cardiac diseases, hypercholesterolemia, malignancy, and post-lymphadenectomy status did not influence the length of the hospitalization (Table 2).

Chills at the time of admission were associated with significantly longer hospitalization $(\mathrm{p}=0.02)$. Moreover, patients with lymphadenopathy stayed in the hospital longer than those without lymphadenopathy, but the difference did not reach statistical significance (17 days compared to 9.5 days, respectively; $\mathrm{p}=0.06$; Table 2 ).

The hospitalization duration varied with the clinical subtype of erysipelas $(p=0.009)$. The post hoc tests revealed that patients with a gangrenous variant of erysipelas stayed in the hospital significantly longer than patients with an erythematous subtype $(\mathrm{p}=0.03$; Table 2$)$. Furthermore, patients with disease localized to the lower extremities were hospitalized significantly longer than patients with erysipelas on other parts of the body $(\mathrm{p}=0.01$; Table 2).

During hospitalization, a cutaneous swab was taken from 16 patients. A positive culture result was associated 
Table 1. Demographic and clinical characteristics of the patients

\begin{tabular}{|c|c|}
\hline Variable & Number of patients (\%) \\
\hline \multicolumn{2}{|l|}{ Sex } \\
\hline Female & $63(46.7 \%)$ \\
\hline Male & $72(53.3 \%)$ \\
\hline \multicolumn{2}{|l|}{ Age } \\
\hline$<20$ years & $1(0.7 \%)$ \\
\hline $21-30$ years & $5(3.7 \%)$ \\
\hline $31-40$ years & $12(8.9 \%)$ \\
\hline $41-50$ years & $15(11.1 \%)$ \\
\hline $51-60$ years & $32(23.7 \%)$ \\
\hline $61-70$ years & $31(23.0 \%)$ \\
\hline $71-80$ years & $24(17.8 \%)$ \\
\hline$>80$ years & $15(11.1 \%)$ \\
\hline \multicolumn{2}{|c|}{ Localization of erysipelas } \\
\hline Face & $16(10.5 \%)$ \\
\hline Upper extremity & $3(2.0 \%)$ \\
\hline Trunk & $9(5.9 \%)$ \\
\hline Lower extremity & $121(79.1 \%)$ \\
\hline More than 1 part of the body & $4(2.6 \%)$ \\
\hline \multicolumn{2}{|l|}{ Subtype } \\
\hline Erythematous & $108(70.6 \%)$ \\
\hline Bullous & $26(17.0 \%)$ \\
\hline Hemorrhagic & $8(5.2 \%)$ \\
\hline Gangrenous & $3(2.0 \%)$ \\
\hline Bullo-hemorrhagic & $8(5.2 \%)$ \\
\hline \multicolumn{2}{|c|}{ General symptoms } \\
\hline Fever & $100(65.4 \%)$ \\
\hline Chills & $32(20.9 \%)$ \\
\hline Weakness & $42(27.5 \%)$ \\
\hline Nausea & $9(5.9 \%)$ \\
\hline Lymphadenopathy & $11(7.2 \%)$ \\
\hline \multicolumn{2}{|l|}{ Comorbidities } \\
\hline Tinea pedis & $8(5.2 \%)$ \\
\hline Diabetes mellitus & $40(26.1 \%)$ \\
\hline Hypertension & $79(51.6 \%)$ \\
\hline Hypercholesterolemia & $19(12.4 \%)$ \\
\hline Chronic venous insufficiency of lower legs & $30(19.6 \%)$ \\
\hline Anemia & 54 (35.3\%) \\
\hline Cardiac disease & $50(32.7 \%)$ \\
\hline Malignancy & $22(14.4 \%)$ \\
\hline Post-lymphadenectomy status & $10(6.5 \%)$ \\
\hline Chronic renal disease & $14(9.2 \%)$ \\
\hline Obesity & $19(12.4 \%)$ \\
\hline \multicolumn{2}{|c|}{ Antibiotic therapy before admission } \\
\hline Yes & $67(43.8 \%)$ \\
\hline No & $86(56.2 \%)$ \\
\hline
\end{tabular}

Table 2. Length of hospitalization according to different variables. Localization in the lower extremities, erysipelas gangrenous, the presence of chills, tinea pedis, anemia, positive swab culture, elevated CRP, and leukocytosis were determined as factors associated with prolonged hospitalization

\begin{tabular}{|c|c|c|}
\hline Variable & $\begin{array}{l}\text { The median } \\
\text { length of stay in } \\
\text { the hospital (IQR) }\end{array}$ & $\mathrm{p}$-value \\
\hline \multicolumn{3}{|c|}{ Sex } \\
\hline Female & $9(7-14)$ & \multirow{2}{*}{0.8} \\
\hline Male & $10(7-14)$ & \\
\hline \multicolumn{3}{|c|}{ Localization of erysipelas } \\
\hline Face & $7(6-8.5)$ & \multirow{5}{*}{0.01} \\
\hline Upper extremity & $7(6-18)$ & \\
\hline Trunk & $9(7-10)$ & \\
\hline Lower extremity & $11(7-15)$ & \\
\hline More than 1 part of the body & $10(7-14)$ & \\
\hline \multicolumn{3}{|c|}{ Subtype } \\
\hline Erythematous & $9(6.5-12.5)$ & \multirow{5}{*}{$0.009^{*}$} \\
\hline Bullous & $11.5(8-19)$ & \\
\hline Hemorrhagic & $13.5(9.5-15)$ & \\
\hline Gangrenous & $25(19-28)$ & \\
\hline Bullous-hemorrhagic & $14(10-20)$ & \\
\hline \multicolumn{3}{|c|}{ General symptoms } \\
\hline $\begin{array}{l}\text { Fever } \\
\text { No fever }\end{array}$ & $\begin{array}{c}9(7-14) \\
10(7-14)\end{array}$ & 0.9 \\
\hline $\begin{array}{l}\text { Chills } \\
\text { No chills }\end{array}$ & $\begin{array}{l}12(9-15) \\
9(7-14)\end{array}$ & 0.02 \\
\hline $\begin{array}{l}\text { Malaise } \\
\text { No malaise }\end{array}$ & $\begin{array}{l}9.5(8-15) \\
10(7-14)\end{array}$ & 0.3 \\
\hline $\begin{array}{l}\text { Nausea } \\
\text { No nausea }\end{array}$ & $\begin{array}{c}9(9-15) \\
10(7-14)\end{array}$ & 0.5 \\
\hline $\begin{array}{l}\text { Lymphadenopathy } \\
\text { No lymphadenopathy }\end{array}$ & $\begin{array}{l}17(7-21) \\
9.5(7-14)\end{array}$ & 0.06 \\
\hline \multicolumn{3}{|c|}{ Comorbidities } \\
\hline Tinea pedis & $15.5(13.5-20)$ & 0.002 \\
\hline Diabetes mellitus & $10(7-13.5)$ & 0.9 \\
\hline Hypertension & $10(7-15)$ & 0.1 \\
\hline Hypercholesterolemia & $10(7-14)$ & 0.9 \\
\hline Chronic venous insufficiency & $11(7-14)$ & 0.7 \\
\hline Anemia & $11(9-15)$ & 0.03 \\
\hline Cardiac disease & $10(7-14)$ & 0.9 \\
\hline Malignancy & $9(5-10)$ & 0.07 \\
\hline Post-lymphadenectomy status & $10(9-11)$ & 0.9 \\
\hline Chronic renal disease obesity & $9.5(7-11)$ & 0.5 \\
\hline Obesity & $11(8-15)$ & 0.3 \\
\hline \multicolumn{3}{|c|}{ Laboratory tests } \\
\hline Positive swab culture & $17.5(9.5-21)$ & 0.007 \\
\hline Elevated ERS & $10(7-15)$ & 0.3 \\
\hline Elevated CRP (>100 mg/L) & $11(8-17)$ & 0.02 \\
\hline Leukocytosis & $11(8-15)$ & 0.005 \\
\hline Elevated procalcitonin & $13(7-15)$ & 0.97 \\
\hline
\end{tabular}

IQR - interquartile range; ERS - erythrocyte sedimentation rate; CRP - C-reactive protein; * $p$-value obtained with the Kruskal-Wallis test; ${ }^{* *} p$-value obtained with post hoc test. Values in bold are statistically significant. 
with longer hospitalization (17.5 days, IQR = 9.5-21; $\mathrm{p}=0.007)$. Regarding markers of inflammation on admission, 87 (56.9\%) patients had leukocytosis (median $10.89 \times 10^{3}$ cells $/ \mu \mathrm{L}, \mathrm{IQR}=8.3-14.3 ;$ range $3.04-37.8 \times 10^{3}$ cells $/ \mu \mathrm{L}), 140$ (91.5\%) had elevated serum CRP levels (median $82.9 \mathrm{mg} / \mathrm{L}, \mathrm{IQR}=35.5-158.8$; range $0.4-530.0 \mathrm{mg} / \mathrm{L}$ ), $112(73.2 \%$ ) had increased ESR (median $67 \mathrm{~mm} / \mathrm{h}$, IQR = 35-86; range $4-125 \mathrm{~mm} / \mathrm{h}$ ), and 73 (47.7\%) had elevated procalcitonin values (median $0.2 \mathrm{ng} / \mathrm{mL}$, IQR = 0.070.83; range 0.01-14.7 ng/mL). Patients with leukocytosis were hospitalized significantly longer than patients with a normal white blood cell range $(p=0.005)$, and an elevated CRP level over $100 \mathrm{mg} / \mathrm{L}$ significantly increased the length of stay in the ward ( $\mathrm{p}=0.02$; Table 2$)$.

Before the admission, 67 (43.8\%) patients used an oral antibiotic treatment. Antibiotic therapy before hospitalization did not affect the length of stay $(\mathrm{p}=0.8$; Table 2$)$. As the first-line treatment during hospitalization, the most commonly chosen antibiotic was clindamycin $(n=41$; $26.8 \%$ ), followed by amoxicillin with clavulanic acid ( $\mathrm{n}=34 ; 22.2 \%)$. Twenty-six (17.0\%) patients were treated with cephalosporins, 23 (15.0\%) with penicillin, and 20 (13.1\%) with lincomycin. Eight (5.2\%) were treated with combination antibiotic therapy since day 1 . There were no statistically significant differences between the length of stay and the first-line antimicrobial therapy $(\mathrm{p}=0.1)$. However, patients treated with clindamycin during their hospitalization, regardless of whether it was a first-line or subsequent antibiotic, spent significantly more time in the ward than patients treated with other antimicrobial medications $(\mathrm{p}=0.005)$.

\section{Discussion}

Prolonged hospitalization of patients with erysipelas is a significant financial burden for the healthcare system. Higher costs are associated with additional tests and examinations, long antibiotic therapy courses, and a delay in patient's return to activities and work.

The current results did not demonstrate the superiority of any of the antibiotics in terms of hospitalization time. However, it was observed that patients treated with clindamycin were hospitalized longer than patients treated with other antibiotics. Brindle et al. ${ }^{14}$ analyzed 43 studies with 5999 patients to examine the optimum antibiotic treatment for erysipelas and cellulitis. This review also did not determine an advantage for using any group of antibiotics or antibiotic combination therapy. The German guidelines recommend intravenous treatment with crystalline penicillin $G$ for 7-10 days. In the case of penicillin allergy, treatment with clindamycin for 7-10 days is recommended..$^{13}$ Since the bacterial sensitivity to a particular antibiotic may change over time and the treatment is often empirical, knowledge of the most common local pathogens causing erysipelas may help in choosing the right therapeutic option.
In the current research, it was observed that tinea pedis is one of the factors associated with a prolonged stay in the hospital. Pavlotski et al. ${ }^{15}$ also identified tinea pedis as a contributing factor for recurrent episodes of erysipelas. Moreover, obesity, venous insufficiency, and lymphedema were mentioned as recurrence risk factors. ${ }^{15} \mathrm{~A}$ recent publication by Korecka et al. ${ }^{16}$ also found tinea pedis as an important risk factor for the disease, not only for the first episode, but also for recurrent erysipelas.

Another factor identified in the current study that significantly affected prolonged stay in the ward was anemia. While there is less evidence in the literature to support the association between these variables, the relationship may be due to a lower oxygen supply, ischemia and more severe erysipelas caused by a low hemoglobin concentration.

Roda et al. ${ }^{17}$ found that positive culture results, CRP and leukocytosis were characteristics associated with a prolonged stay in the hospital. In the current study, it was also observed that these factors were associated with longer hospitalization. Other factors affecting prolonged hospitalization were advanced age, previous episodes of erysipelas/ cellulitis, and the presence of complications. ${ }^{17}$

It was also found that localization to the lower extremities and increased levels of inflammatory markers were risk factors for a prolonged hospital stay. These findings are in line with other studies. ${ }^{18}$ In contrast, correlations between the length of hospitalization and fever on admission, abscesses, obesity, diabetes mellitus, and thrombosis, that have been reported in other studies, were not observed here. ${ }^{18}$

\section{Limitations}

We realize that our research carries the risk of bias. The main limitation of the present study is the possible exclusion of potential confounding factors for prolonged hospitalization, such as the adverse social context or the occurrence of other complications not directly related to erysipelas. Another limitation is the possible misclassification of a certain number of cases. Most cases were classified as erysipelas on clinical grounds only and this condition cannot always be clearly distinguished from cellulitis. Due to these limitations, further prospective research should be carried out to verify our conclusions.

\section{Conclusions}

Erysipelas is an infectious disease that, due to its severe course, often requires hospitalization. Prolonged hospitalization is a burden for the healthcare system and an additional risk for patients. Here, we revealed that some factors, such as the clinical features of the disease, laboratory test results, and the choice of treatment, have an impact on the length of hospitalization of patients with erysipelas. In clinical practice, patients with the above risk factors should receive special care. 


\section{ORCID iDs}

Magdalena Łyko (D) https://orcid.org/0000-0001-9622-1593

Mateusz Kaczmarek (D) https://orcid.org/0000-0003-2711-6452

Polina Nekrasova (D) https://orcid.org/0000-0002-8795-6894

Anita Hryncewicz-Gwóźdź (D) https://orcid.org/0000-0002-1601-471X

Joanna Maj (iD https://orcid.org/0000-0001-8300-8208

Alina Jankowska-Konsur (D) https://orcid.org/0000-0003-4944-5388

\section{References}

1. Blaeckberg A, Trell K, Rasmussen M. Erysipelas: A large retrospective study of aetiology and clinical presentation. BMC Infect Dis. 2015;15:402. doi:10.1186/s12879-015-1134-2

2. Celestin R, Brown J, Kihiczak G, Schwartz RA. Erysipelas: A common potentially dangerous infection. Acta Dermatovenerol Alp Pannonica Adriat. 2007;16(3):123-127. PMID:17994173

3. Eriksson B, Jorup-Roenstroem C, Karkkonen K, Sjoeblom AC, Holm SE. Erysipelas: Clinical and bacteriologic spectrum and serological aspects. Clin Infect Dis. 1996;23(5):1091-1098. doi:10.1093/clinids/23.5.1091

4. Socan K, Socan M. Trends in the epidemiology of erysipelas in Slovenia. Acta Dermatovenerol Alp Pannonica Adriat. 2018;27(1):1-4. PMID: 29589637

5. Bernard P, Bedane C, Mounier M, Denis F, Catanzano G, Bonnetblanc JM. Streptococcal cause of erysipelas and cellulitis in adults: A microbiologic study using a direct immunofluorescence technique. Arch Dermatol. 1989;125(6):779-782. PMID:2658843

6. Trell K, Rignér S, Wierzbicka M, Nilson B, Rasmussen M. Colonization of $\beta$-hemolytic streptococci in patients with erysipelas: A prospective study. Eur J Clin Microbiol Infect Dis. 2019;38(10):1901-1906. doi:10.1007/s10096-019-03625-9

7. Brishkoska-Boshkovski V, Dimitrovska I, Kondova-Topuzovska I. Clinical presentation and laboratory characteristics in acute and recurrent erysipelas. Open Access Maced J Med Sci. 2019;7:771-774. doi:10.3889/ oamjms.2019.213

8. Bonnetblanc JM, Bedane C. Erysipelas: Recognition and management. Am J Clin Dermatol. 2003;4(3):157-163. doi:10.2165/00128071200304030-00002
9. Inghammar M, Rasmussen M, Linder A. Recurrent erysipelas: Risk factors and clinical presentation. BMCInfect Dis. 2014;14:270. doi:10.1186/ 1471-2334-14-270

10. Eron LJ, Lipsky BA, Low DE, et al. Managing skin and soft tissue infections: Expert panel recommendations on key decision points. J Antimicrob Chemother. 2003;52(Suppl 1):i3-i17. doi:10.1093/jac/dkg466

11. Stevens DL, Bisno AL, Chambers HF, et al; Infectious Diseases Society of America. Practice guidelines for the diagnosis and management of skin and soft tissue infections: 2014 update by the Infectious Diseases Society of America [published correction appears in: Clin Infect Dis. 2015;60:1448. Dosage error in article text]. Clin Infect Dis. 2014;59(2): e10-e52. doi:10.1093/cid/ciu444

12. Kwak YG, Choi SH, Kim T, et al. Clinical guidelines for the antibiotic treatment for community-acquired skin and soft tissue infection. Infect Chemother. 2017;49(4):301-325. doi:10.3947/ic.2017.49.4.301

13. Sunderkoetter C, Becker K, Eckmann C, Graninger W, Kujath P, Schoefer H. Calculated initial parenteral treatment of bacterial infections: Skin and soft tissue infections. GMS Infect Dis. 2020;8:Doc11. doi:10.3205/id000055

14. Brindle R, Williams OM, Barton E, Featherstone P. Assessment of antibiotic treatment of cellulitis and erysipelas: A systematic review and meta-analysis. JAMA Dermatol. 2019;155(9):1033-1040. doi:10.1001/ jamadermatol.2019.0884

15. Pavlotsky F, Amrani S, Trau H. Recurrent erysipelas: Risk factors. J Dtsch Dermatol Ges. 2004;2(2):89-95. doi:10.1046/j.1439-0353.2004. 03028.x

16. Korecka K, Mikiel D, Banaszak A, Neneman A. Fungal infections of the feet in patients with erysipelas of the lower limb: Is it a significant clinical problem? Infection. 2021 [online ahead of print]. doi:10. 1007/s15010-021-01582-0

17. Roda A, Pinto AM, Filipe AR, Travassos AR, Freitas JP, Filipe P. Clinical and laboratory factors associated with prolonged hospital stay among patients with cellulitis/erysipelas [in Spanish]. Acta Med Port. 2019;32:448-452. doi:10.20344/amp.10735

18. Kozłowska D, Myśliwiec H, Kiluk P, Baran A, Milewska AJ, Flisiak I. Clinical and epidemiological assessment of patients hospitalized for primary and recurrent erysipelas. Przegl Epidemiol. 2016;70(4):575-584. PMID:28221013 